\title{
A Quantitative Assessment of Financial Conditions in Asia
}

Carolina Osorio, Runchana Pongsaparn, D. Filiz Unsal 


\title{
IMF Working Paper
}

Asia and Pacific Department

\section{A Quantitative Assessment of Financial Conditions in Asia Prepared by Carolina Osorio, Runchana Pongsaparn, D. Filiz Unsal}

Authorized for distribution by Roberto Cardarelli

July 2011

\begin{abstract}
We propose a new Financial Condition Index (FCI) for Asian economies based on two different methodologies: a VAR model and a Dynamic Factor Model. The paper shows that this index has predictive power in forecasting GDP growth and may be thus used as a leading indicator. Based on the FCI, financial conditions in Asia tightened substantially earlier in the global crisis, reflecting losses in the stock markets and tighter credit conditions. In early 2010, financial conditions in Asia recovered rapidly and reached precrisis levels, thanks to accommodative monetary policies and a rapid rebound in regional equity markets.
\end{abstract}

JEL Classification Numbers: E17, E44, E5

Keywords: Financial conditions index, VAR, Dynamic Factor Analysis

Authors' E-Mail Addresses: carolina.osorio@economics.ox.ac.uk, runchanp@bot.or.th, dunsal@imf.org

\section{This Working Paper should not be reported as representing the views of the IMF.} The views expressed in this Working Paper are those of the author(s) and do not necessarily represent those of the IMF or IMF policy. Working Papers describe research in progress by the author(s) and are published to elicit comments and to further debate. 


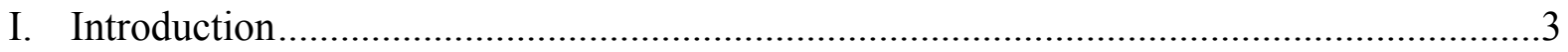

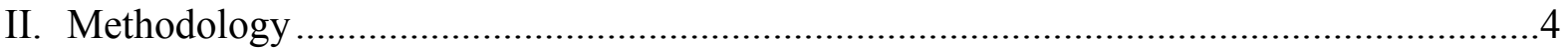

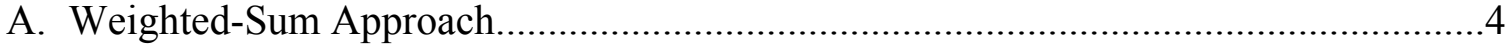

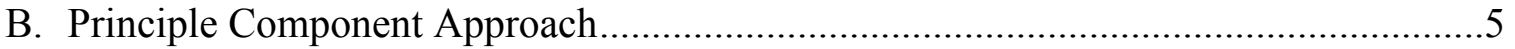

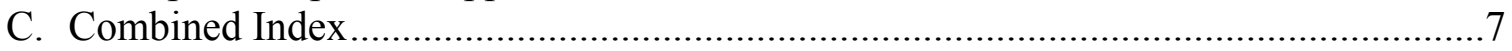

III. Evaluating the Financial Condition Index ..........................................................11

IV. Developments of Financial Conditions in Asia over the Course of the Global Crisis ......14

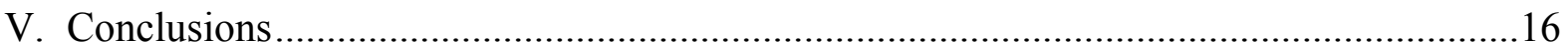

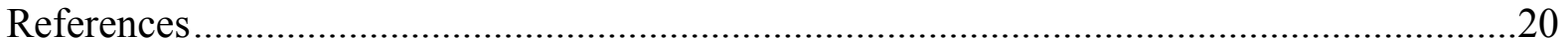

Figures

1. Selected Asia: Financial Condition Index (FCI) and GDP Growth................................

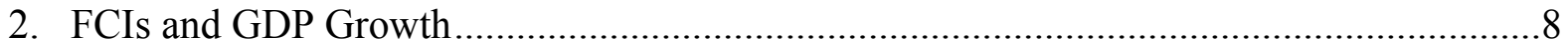

3. Relative Contribution of Financial Variables in FCI ...................................................10

4 Contribution of Exchange Rate and Stock Prices to FCI and GDP Growth Volatility .....10

5. Average Reduction in GDP Growth Over the Next Four Quarters From Tightening

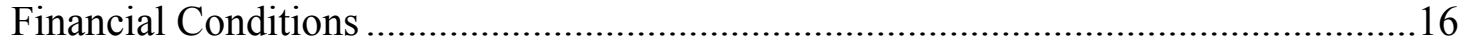

Tables

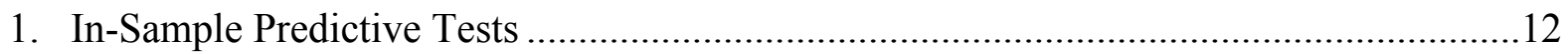

2. Out-of-Sample Predictive Tests ..............................................................................13

3. Correlation of Real GDP Outturns and Its Real-Time Forecasts: With and Without

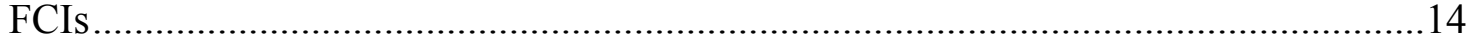

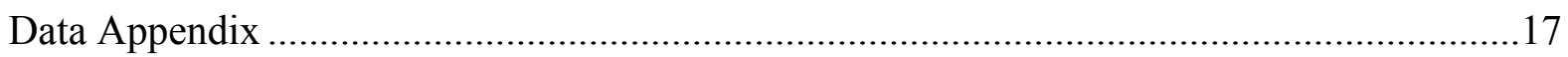




\section{INTRODUCTION}

The 2008 global financial crisis emphasized the importance of identifying and assessing the linkages between financial conditions and the real economy. In many Asian economies, a sudden tightening of financial conditions at end-2008 contributed to a sharp decline in output. An unprecedented monetary policy response and strong rebound in equity markets helped to provide an important backstop to economic activity in Asia, and sowed the seeds of an exceptionally fast recovery since mid 2009. As the recovery gained traction, many central banks across Asia began to normalize monetary policy stances, although at a very gradual pace, and the emergence of inflationary pressures at the end of 2010 induced many regional economies to accelerate the pace of monetary tightening early in 2011.

The change in the policy interest rates represents only one dimension of the evolution of overall financial conditions in the economy. The impact of policy rates on other financial variables - in particular, credit, asset prices, and the exchange rate - is also an important part of the monetary policy transmission mechanism. If the transmission from policy rates to these financial variables is incomplete or unstable, assessing overall financial conditions requires looking at these variables as well.

Against this background, the objective of this paper is to provide a quantitative assessment of overall financial conditions in 13 Asian economies by developing a new index of financial conditions. A Financial Condition Index (FCI) is a tool to extract information contained in the current values of a series of financial variables about the future state of the economy. An ideal FCI should measure exogenous changes in financial conditions, rather than changes in financial variables that reflect the evolution of the business cycle. ${ }^{1}$ Hence, the endogenous component of financial conditions should be removed in the construction of the index. The selection of financial variables in the FCIs reflects their linkages to economic growth. Generally, FCIs capture the linkages between financial conditions and economic activity via three main channels: investment (through quantity and cost of capital), consumption (through wealth, confidence, and income effects), and trade channels (through price competitiveness of tradable goods).

In the literature, a variety of methodologies for constructing FCIs have been developed, but there are two prominent approaches: a weighted-sum approach and a principal-components approach. In the weighted-sum approach, each financial variable in the index is assigned a weight that reflects an estimate of its impacts on real GDP. These estimates are obtained through simulations of large-scale macroeconomic models, or through the estimation of reduced-form demand equations or vector autoregression (VAR) models. Examples of FCIs using a weighted-sum approach are the indexes estimated by Macroeconomic Advisors, the OECD, Goldman Sachs, Bloomberg FCI, and Citigroup.

\footnotetext{
${ }^{1}$ See Hatzius and others (2010) and Dudley (2010).
} 
The second approach is based on the principal component analysis, whereby a common factor is estimated from a group of several financial variables and interpreted as the unobserved common variable underlying the variation of all the financial variables included in the index. Examples of this type of FCIs include the indexes estimated by the Deutsche Bank and the Federal Reserve Bank of Kansas City.

The paper is partitioned into four main sections. The next section gives more details on the methodology used in the construction of the index. The third section investigates the performance of FCIs as an input into economic forecasts. The following section examines the evolution of financial conditions in Asia in the two years after the global financial crisis, and the impact of such developments on GDP.

\section{Methodology}

We develop new FCIs for a group of 13 Asian economies between 2001 up to the beginning of 2011. ${ }^{2}$ The selection for the sample, which includes Australia, China, Hong Kong SAR, India, Indonesia, Japan, Korea, Malaysia, New Zealand, Philippines, Singapore, Thailand, and Taiwan Province of China, reflects availability of data.

Our paper differs from the existing literature in two ways. First, we employ both the weighted-sum and principal-component approaches in the construction of FCIs, and take the average of the two indices to construct our financial indicator. Second, we control for the endogenous responses of financial variables to economic activity, and therefore our index only presents exogenous changes in financial conditions (see also Hatzius and others, 2010 for a similar point).

\section{A. Weighted-Sum Approach}

We first estimate an FCI as a weighted average of financial variables, where the weights reflect the relative importance of each of these financial variables in affecting output as derived from a VAR model, in line with earlier work by Guichard and Turner (2008) and Swiston (2008).

More specifically, the following system of equations is estimated:

$$
X_{t}=A_{0}+\sum_{i=1}^{p} A_{i} X_{t-i}+B Y_{t}+\varepsilon_{t}
$$

where $X$ is a vector of endogenous variables, $A$ and $B$ are vectors of coefficients, $Y$ is a vector of exogenous variable, and $\varepsilon$ is a vector of error terms. Endogenous variables include GDP, equity prices, prices, the effective exchange rate, the spread of lending rates over policy rates,

\footnotetext{
${ }^{2}$ See the box "A Financial Condition Index for Asia" in the October 2010 Asia and Pacific Regional Economic Outlook.
} 
and bank credit to the private sector. ${ }^{3}$ To construct the weight for each financial variable in the FCI, we use generalized impulse responses, which allow the result to be independent from any specific orderings of the variables in the VAR. The FCI is thus calculated as follows:

$$
\mathrm{FCI} I_{t}=\sum_{j=1}^{n} w_{j}\left(x_{j, t}-\tilde{x}_{j}\right)
$$

where $w_{j}$ is the weight attached to the financial variable $x_{j}$, obtained as the cumulative responses (between 4-6 quarters) of GDP growth to one-unit shock to the variable $x_{j}$, and $\tilde{x}_{j}$ is an average of $x_{j}$ over the whole sample period (1990-2010).

\section{B. Principal Component Approach}

In the principal component approach, the FCI index is constructed in two steps: first, by estimating the unobserved common component of the data using the Generalized Dynamic Factor Model (GDFM) developed by Forni and Lippi (2005); and second, by regressing the common factor on economic activity variables, namely inflation and GDP growth rates, and taking the residuals. This addresses the endogeneity problem caused by the fact that financial variables partially reflect economic activity.

Unlike the classic factor model, the GDFM combines the approximate static factor model of Chamberlain and Rothschild (1983) and the dynamic factor model of Geweke (1977) and Sargent and Sims (1977) because it allows for weakly serial and cross-sectional correlation between idiosyncratic errors. ${ }^{4}$

Let $y^{j}$ be the data set used for the $j$-th economy:

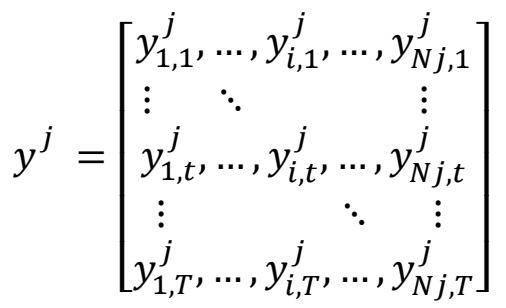

The latter is a balanced panel data set comprised of interest rate spreads of government bonds of different maturity/lending rates over policy rates, the nominal effective exchange rate, nominal credit to the private sector, and stock market indices. ${ }^{5}$

\footnotetext{
${ }^{3}$ See data appendix for details of data.

${ }^{4}$ The use of principle component approach for the estimation of a composite economic indicator dates back to seminal contributions of Stock and Watson (1989, 1998a, 1998b).

${ }^{5}$ In principle, one can add as many variables as available to the dataset and it should be obvious that the results could be sensitive to the selection of variables. In this paper, we work with these four variables in order to 
In the GDFM, each observation $\left(y_{i t}^{j}\right)$, for every time series $i=\left\{1, \ldots, N^{j}\right\}$ and economy $j=\{1, \ldots, J\}$, and across time $t=\{1, \ldots, T\}$, is composed of two mutually orthogonal parts, an idiosyncratic component and a common component. This implies that each data point can be represented as follows:

$$
y_{i, t}^{j}=\chi_{i, t}^{j}+\xi_{i, t}^{j}=b_{i}^{j}(L) f_{t}^{j}(L)+\xi_{i, t}^{j}
$$

where $\chi_{i, t}^{j}$ is a common component driven by a small number $\left(q_{j}\right)$ of common shocks or factors, and each element of $b_{i}^{j}(L)=\left[b_{i, 1}^{j}(L), \ldots, b_{i, q j}^{j}(L)\right]$ is a row vector of the lag polynomials for the $i=\left\{1, \ldots, N^{j}\right\}$ variables. The idiosyncratic component is summarized by $\xi_{i, t}^{j}$, reflecting $N^{j}$ variable-specific shocks. The common factor $\left(f_{t}^{j}\right)$ needs to be estimated through a dynamic principal component analysis. ${ }^{6}$ The first step involves estimating $f_{t}^{j}=$ $\left(f_{1, t}^{j}, \ldots, f_{q j, t}^{j}\right)^{\prime}$, a $q_{j}$-dimensional column vector of common factors across time, for each economy. In our analysis, $q_{j}=1 \forall j \in\{1, \ldots, J\}$, and $f_{t}^{j}$ represents the FCI. ${ }^{7}$

However, since an FCI summarizes the information contained in current financial variables about the future state of the economy, it should not be influenced by past economic activity, which itself predicts future business cycles. To address this endogeneity problem, in the second stage of the estimation process we purge $f_{t}^{j}$ of its endogenous predictive component using standard econometric techniques. Following Hatzius and others (2010), we regress $f_{t}^{j}$ on current and lagged business cycle variables:

$$
f_{t}^{j}=A_{j}(L) Z_{j}+v_{t}^{j}
$$

where $Z_{j}$ denotes a vector of real GDP growth and inflation rates for economy $j$, and $v_{t}^{j}$ is the error term, which is uncorrelated with $Z_{t}$ as well as its lagged values. Therefore, $v_{t}^{j}$ is the FCI reflecting only the exogenous shifts in financial conditions that influence, and predict, future economic activity.

\section{Combined Index}

The combined FCI is constructed for each individual economy based on both the VAR and GDFM approaches. While the VAR approach is simple and intuitive, the relationship between financial variables and GDP is assumed to be static (based on past behavior) as

maintain the consistency of the index with the one constructed using VAR. We use data from 2000 up to the end of 2011. See the data appendix for details.

${ }^{6}$ For a more detailed background discussion, see Forni and Lippi (2001).

${ }^{7}$ See the seminal contributions of Stock and Watson $(1989,1998 \mathrm{a}, 1998 \mathrm{~b}, 2002)$ for the use of principle components in estimating economic indicators. 
reflected in the fixed weights attached to each financial variable. On the other hand, the GDFM approach requires reestimation once a new set of data becomes available. Its strength thus lies in the dynamism of the relationship among financial variables, as well as between financial variables and economic activity. Having constructed two sets of indices based on two different methodologies, we then take the simple average of the two FCIs as a combined FCI for each economy. The final FCI indices are reported for a group of Asia and Pacific economies in Figure 1.

Figure 1. Selected Asia: Financial Condition Index (FCI) and GDP Growth

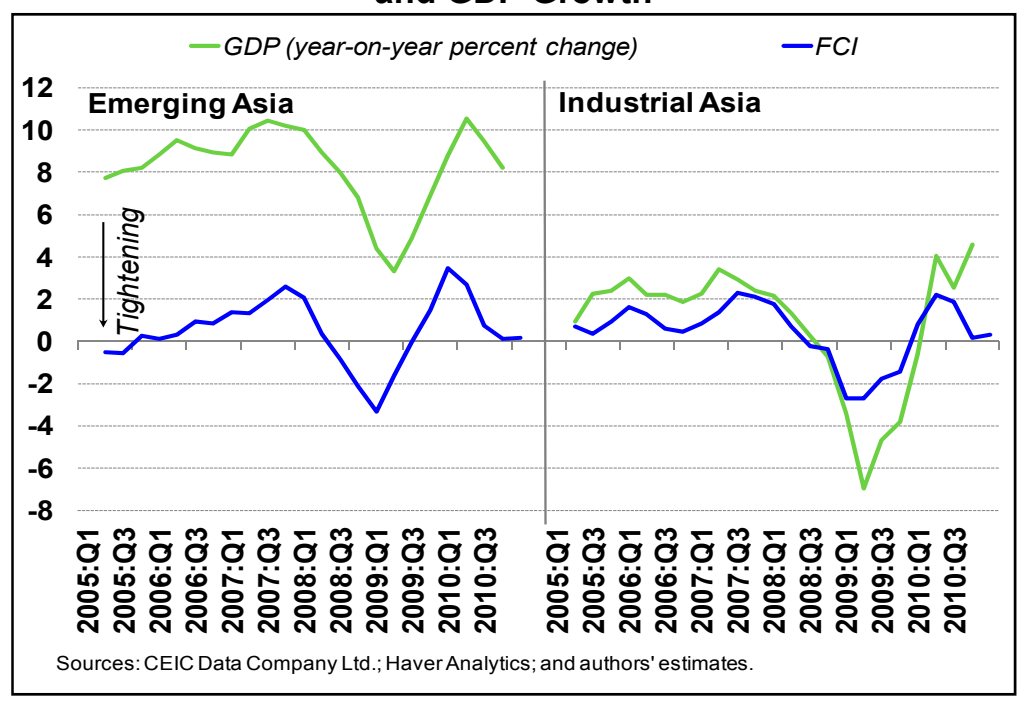

An upward movement of the index suggests more accommodative overall financial conditions, while a decline in the FCI suggests tighter financial conditions that should lead to a deceleration in economic growth.

Indeed, the final index seems to perform well in tracking economic activity. The contemporaneous correlation of the FCI and GDP growth is about 0.6 for emerging Asia and 0.9 for advanced Asia (Figure 1). However, assessing the predictive power of the FCI requires a more in-depth empirical analysis, which is taken up in the next section.

While the movement in FCIs provide a gauge on overall financial conditions, relative contribution of each financial variable provides information on the drivers of financial conditions. Figure 2 reports results for each economy as well as the contributions of each variable (interest rate spread, real exchange rate, credit growth, and stock market indices) to the FCI within the last decade. ${ }^{8}$ This is potentially very useful for policymakers at any point

\footnotetext{
${ }^{8}$ In the case of Australia, the authorities have noted that house prices should have been part of the FCI, as housing wealth represents a large share of personal wealth. However, house prices were excluded from the index due to data limitations in several countries.
} 
in time to gauge which financial variables cause excessively accommodative/tight financial conditions, and hence what type of policy reaction is needed. ${ }^{9}$

Figure 2. FCls and GDP Growth
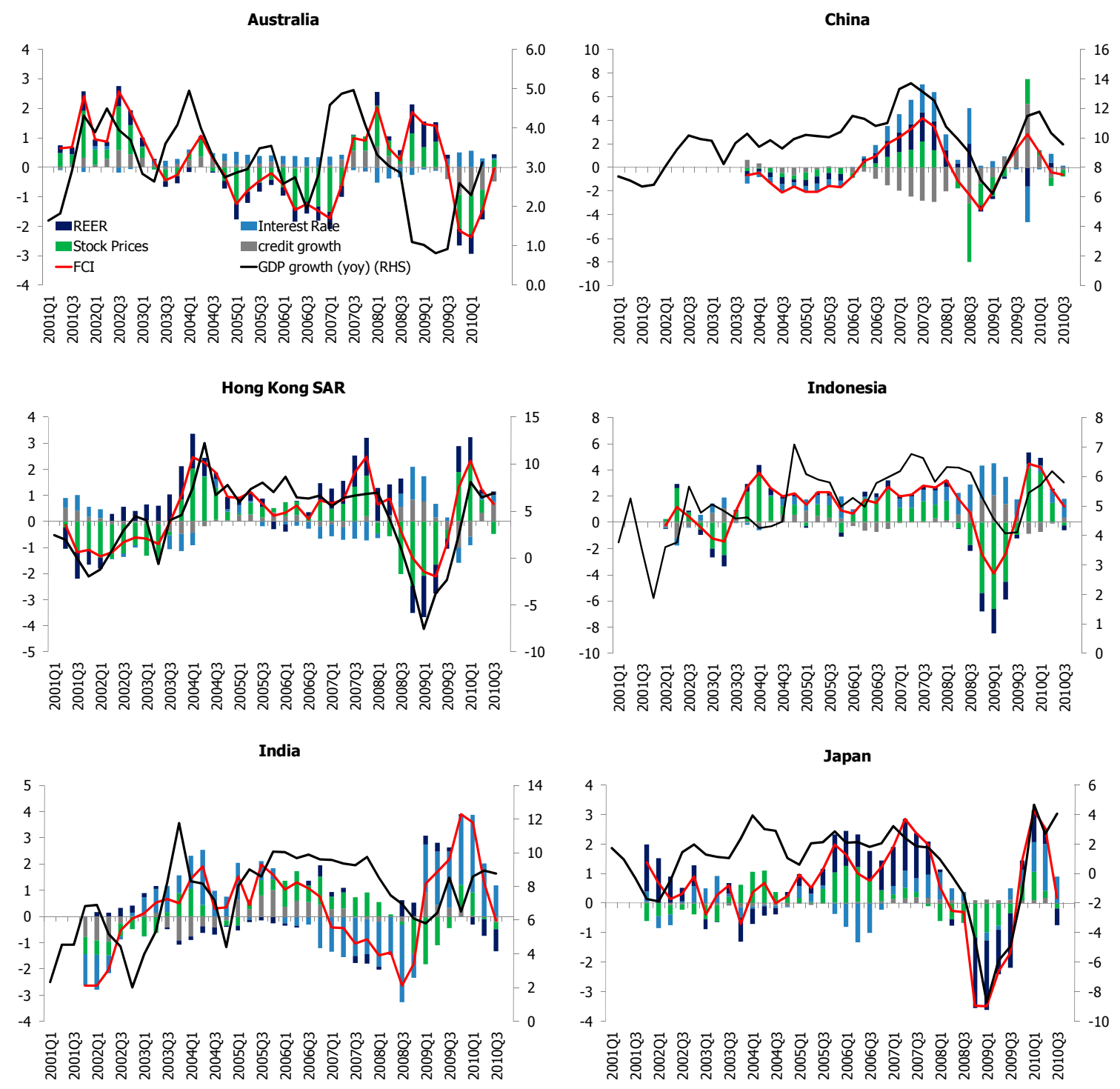

\footnotetext{
${ }^{9}$ See Section IV for a more elaborate discussion on the historical developments of the FCI and its contributing variables in Asia over the last few years.
} 
Figure 2. FCls and GDP Growth (continued)
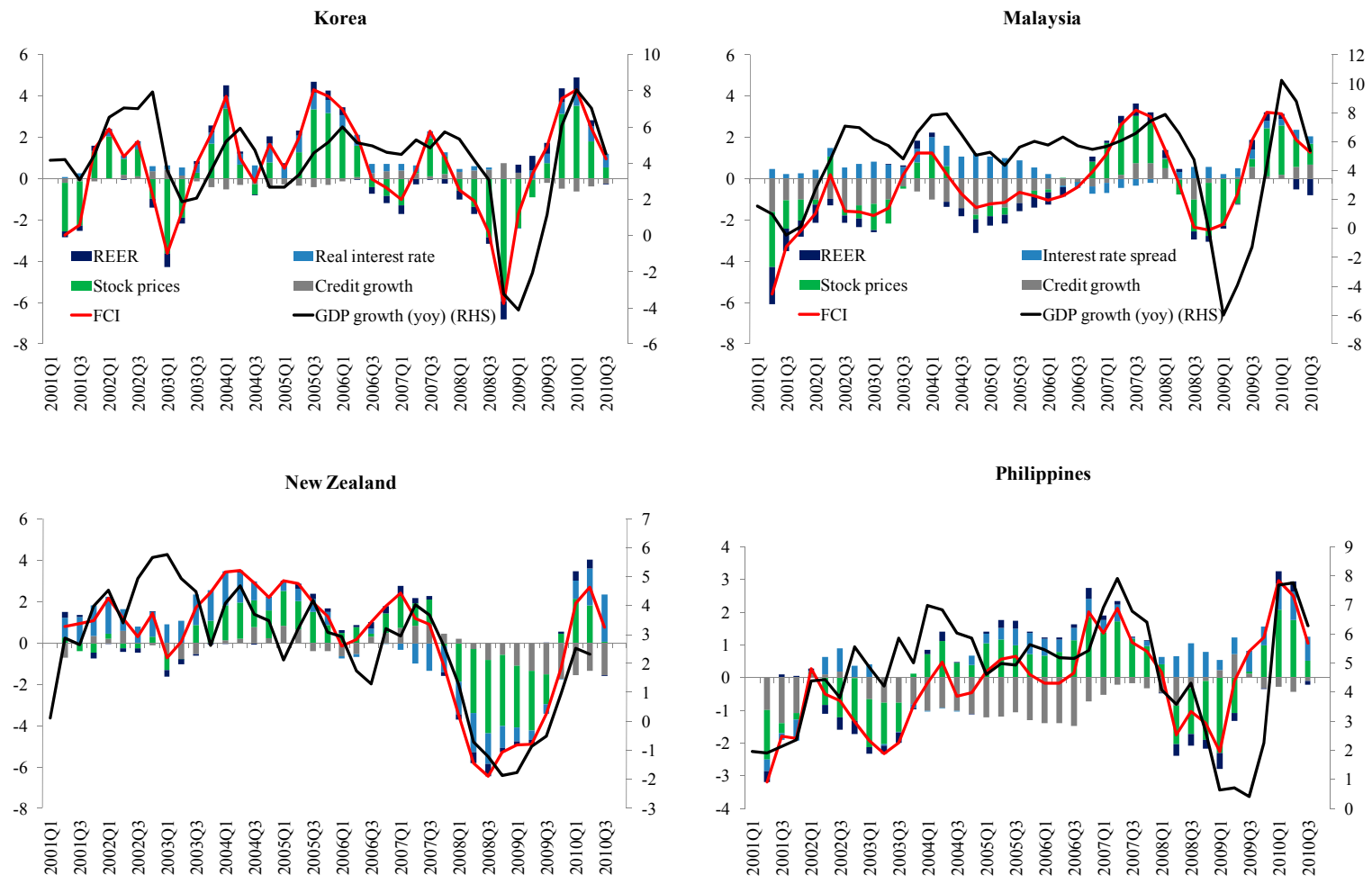

Singapore
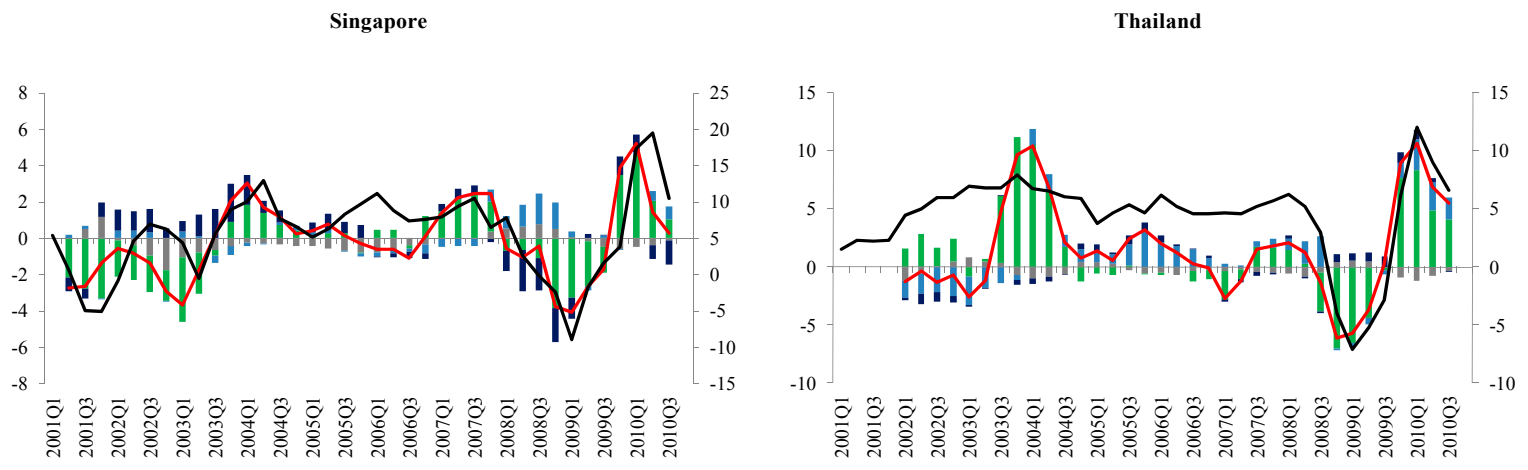

Taiwan Province of China

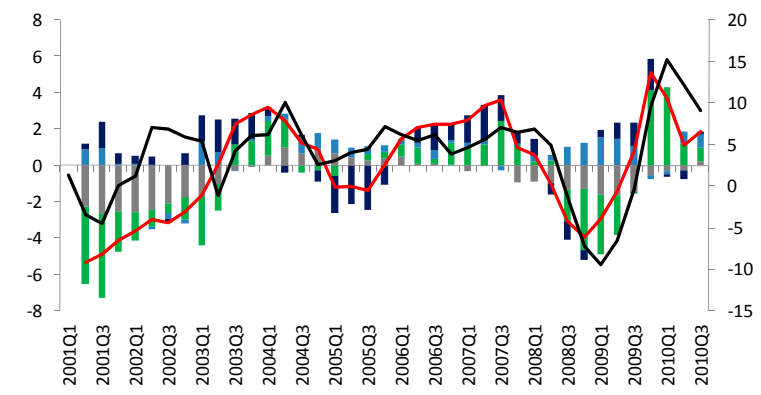

Sources: CEIC Data Company Ltd.; Haver Analytics; and authors' estimates. 
Moreover, differences in the financial and economic structures are reflected in these relative contributions. Figure 3 shows the average contribution of financial variables to the overall FCI of a group of Asia and Pacific economies over the last 10 years. In China and the Philippines, the contribution of credit growth to the FCI is relatively larger, reflecting a relatively greater role for banking intermediation in these economies. On the other hand, the contribution of exchange rates is relatively greater in more export-dependent economies, such as Hong Kong SAR and Taiwan Province of China.

Figure 3. Relative Contribution of Financial Variables in FCl

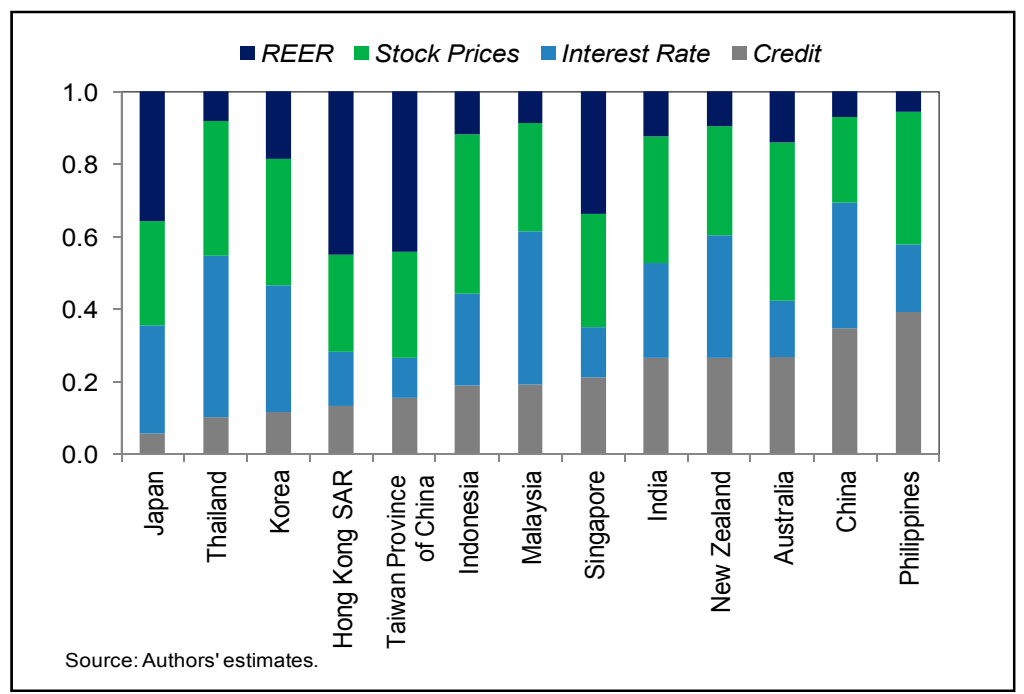

Economies with a relatively greater contribution from exchange rate and equity movements, such as Hong Kong SAR, Taiwan Province of China, and Singapore, tend to experience greater volatility in GDP growth (Figure 4), while economies where changes in interest rates and credit provide a greater contribution to the overall financial conditions, such as India and China, GDP growth is less volatile.

Figure 4. Contribution of Exchange Rate and Stock Prices to FCI and GDP Growth Volatility

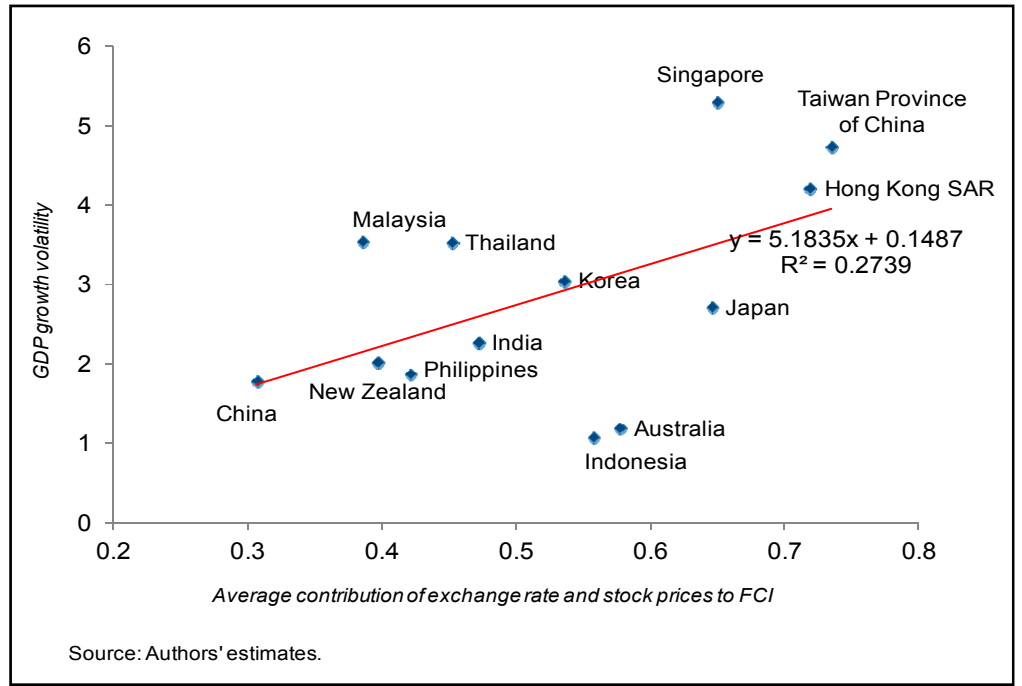




\section{Evaluating THE FinanCial CONDition INDEX}

We carry out formal predictive power tests to investigate the indices' ability to predict GDP growth. The analysis was done both in-sample and out-of-sample, following Bernanke (1990).

Specifically, we estimate the following equation:

$$
\text { growth }_{t+b}=\alpha+\sum_{i=1}^{4} \beta_{i} \text { growth }_{t+1-i}+\sum_{i=1}^{4} \gamma_{i} X_{t+1-i}+\varepsilon_{t}
$$

where $X$ refers to the FCI and growth represents year-on-year real GDP growth. In this equation, the statistical significance of the coefficients of $X,\left(\gamma^{i}\right.$ 's), would indicate that financial condition index has explanatory power in predicting GDP growth, even taking into account the autoregressive part.

Another useful statistic to assess in-sample properties of the indices is to compare partial $R^{2}$ of different indices. Partial $R^{2}$ is the marginal contribution of FCI when growth $t-i$ 's are kept constant; that is, it gives the proportion of unexplained variation of growth that becomes explained when adding FCI. We obtain partial $R^{2}$ by examining the $R^{2}$ of a regression of the residuals of growth with respect to growth $t$ - $i$ 's on the residuals of $F C I$ with respect to growth $t-i$. Although it is useful, the partial $R^{2}$ provides only a performance measure only in relative terms, rather than in absolute terms as in the significance test. Therefore, for in-sample properties, we test both the significance of the FCI coefficients and report the partial $R^{2}$ as well.

For out-of-sample prediction tests, we estimate the same equation recursively and to calculate the root mean squared error (RMSE). RMSEs give the sum of differences between values predicted by a model (5) and the growth values actually observed, and hence are useful for comparing the predictive power of different FCIs.

In-sample statistical properties suggest that the FCIs can help to predict GDP growth (Table 1). Over a forecast horizon of two quarters, statistical tests on the degree of significance (t-statistics and F-statistics) of the coefficients of FCIs confirm that they are powerful leading indicators for GDP growth. ${ }^{10}$ Moreover, the partial $R^{2}$ for the FCIs are in most cases above 0.7 , which implies that the errors in predicting GDP growth, based on its autoregressive parts, could be reduced by 70 percent if a measure of financial conditions is taken into account.

VAR-based and GDFM-based FCIs have comparable performances, while the combined series generally outperform the two in both the in-sample and out-of-sample predictive tests (Table 2). RMSEs are lower in the case of combined series for most of the economies, especially when

\footnotetext{
${ }^{10} \mathrm{We}$ do the same tests for different time horizons up to four quarters. We found that, beyond two quarters, the indices' predictive power decreases as reflected in higher RMSEs, but the performance of the index remains solid on average across economies. We do not report these results here for space considerations, but they are available upon requests from the authors.
} 
compared to the regression in which no measure of financial conditions is considered. This result holds true regardless of whether we include the global financial crisis in our sample or not.

We also conduct real-time forecasting experiments with the FCIs. The real-time forecasts are constructed using the exact information that was available to a real-time forecaster at a particular point in time. Once we construct the real-time forecasts, we take the correlations with the outturns and report in Table 3. This analysis confirms the previous results; if the FCIs are used in GDP forecasting, the correlation of the GDP forecasts in real time and actual GDP increases substantially, from the average of 0.68 to 0.87 .

Table 1. In-Sample Predictive Tests

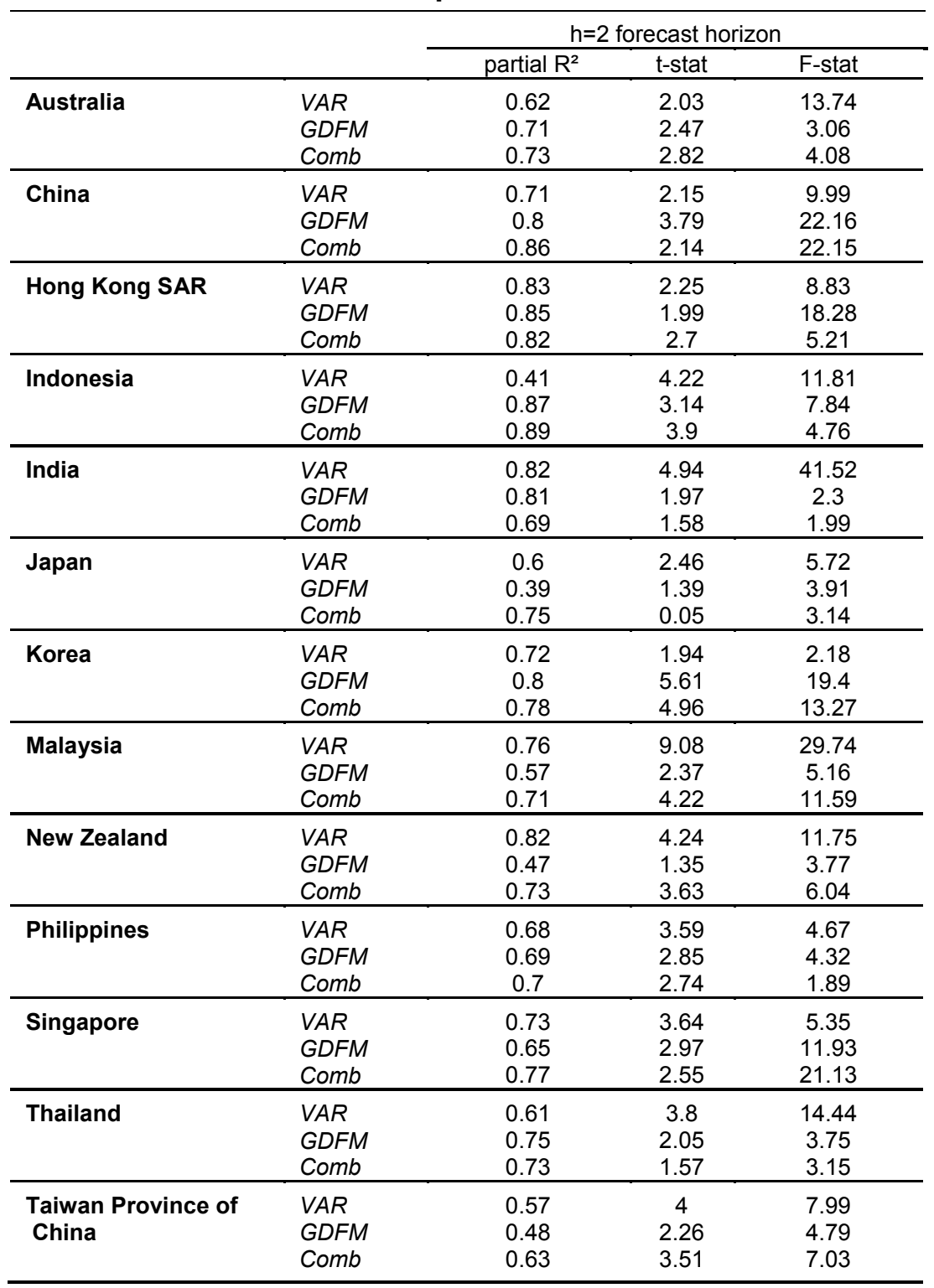

Source: Authors' estimates. 
Table 2. Out-of-Sample Predictive Tests

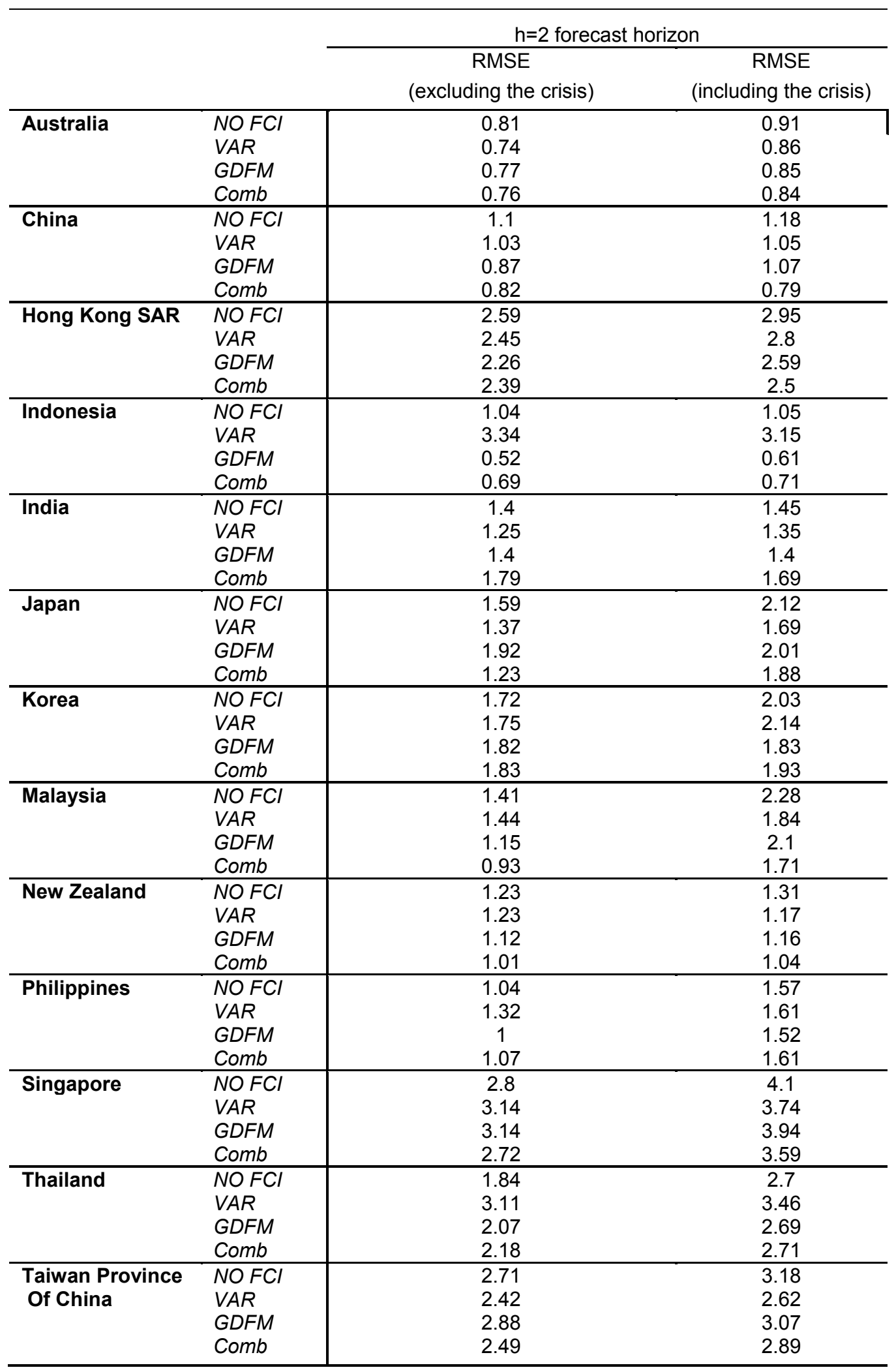

Source: Authors' estimates. 
Table 3. Correlation of Real GDP Outturns and Its Real-Time Forecasts: With and Without FCls

\begin{tabular}{lcc}
\hline & Without FCls & With FCls \\
\hline Australia & 0.68 & 0.86 \\
China & 0.58 & 0.97 \\
Hong Kong SAR & 0.71 & 0.92 \\
Indonesia & 0.6 & 0.76 \\
India & 0.77 & 0.88 \\
Japan & 0.74 & 0.84 \\
Korea & 0.7 & 0.85 \\
Malaysia & 0.73 & 0.9 \\
New Zealand & 0.76 & 0.88 \\
Philippines & 0.56 & 0.72 \\
Singapore & 0.55 & 0.81 \\
Thailand & 0.69 & 0.88 \\
Taiwan Province of China & 0.76 & 0.85 \\
\hline
\end{tabular}

Source: Authors' estimates.

\section{The Developments of Financial Conditions in ASIA OVER the Course of The GlobAl CRISIS}

In this section, we provide an overview of the changes in financial conditions in Asia during the global financial crisis (up to 2010:Q4) to illustrate possible uses and interpretations of the FCI. We divide our analysis in four parts: precrisis, financial crisis, recovery, and normalization.

\section{Precrisis (2006-08:Q2)}

In the precrisis period, overall financial conditions in Asia were relatively accommodative, driven largely by favorable movements in equity markets as well as credit condition. In some economies, especially China, Hong Kong SAR, Japan, and Taiwan Province of China, relatively weaker real exchange rates also contributed positively to overall financial conditions. During this period, monetary policy was tightened in many Asian economies to curb inflationary pressures. Generally, precrisis local peaks in FCIs were achieved in late 2007, although the timing differs across economies, with industrial Asia reaching a peak earlier than emerging Asia. FCIs' local peaks were found to lead GDP growth's local peaks by one to two quarters in many cases, which confirms their leading indicator property. 


\section{Financial Crisis (2008:Q3-2009:Q1)}

As the crisis accelerated at end-2008, market confidence collapsed and the loss in risk appetite led to a sharp pullout of funds from Asia. The decline in stock market valuations, along with tighter credit condition in some economies, contributed to a sharp tightening of financial conditions in late 2008 and early 2009. The strong monetary policy easing could not offset the negative impact from the adverse movements in equity markets and credit conditions. The trough in FCIs was reached in 2008:Q4/2009:Q1. Then again, the trough in GDP growth was reached one to two quarters later, in most cases.

\section{Recovery (2009:Q2-2010:Q1)}

Thanks to the strong policy reactions and rapid recovery in equity markets, financial conditions eased significantly late in 2009, as shown by the strong rebound of FCIs since their trough in all Asian and Pacific economies. In India, Indonesia, Korea, the Philippines, and Thailand, the FCI surpassed the precrisis levels in 2009:Q4. In addition to the strong pick-up in stock prices and the impulse from accommodative monetary policy stances, the exchange rate depreciation in the second half of 2009 contributed positively to FCIs, particularly in Australia, Korea, and Taiwan Province of China. Generally, FCIs reached their local peak in 2009:Q4/2010:Q1, while GDP growth reached a local peak the following quarter later in many cases.

\section{Normalization (2010:Q2 onwards)}

Financial conditions in Asia generally started to tighten over the course of 2010, despite the improvement in credit growth since mid 2010. Equity gains began to stabilize in 2010 in most Asian economies - in part owing to negative spillovers from the euro debt crisis. Much of the Asia and Pacific region saw an appreciation of exchange rates in real terms, at the time when a slow normalization in policy rates also began. The tightening forces from stable equity markets, stronger exchange rates, and higher policy rates have been somewhat offset by the continued recovery in credit, particularly in emerging Asia.

To assess the impact of tighter financial conditions on growth, we simulated the evolution of GDP growth under two scenarios for the second half of 2010: one in which the FCI remains constant at the level of 2010:Q2 and one in which the FCI ease to the level of 2010:Q1. We find that in the second scenario, GDP growth accelerates by about one-half of a percentage point in the next four quarters (see Figure 5). 
Figure 5. Average Reduction in GDP Growth Over 2010:Q2-2011:Q2 from Tighter Financial Conditions

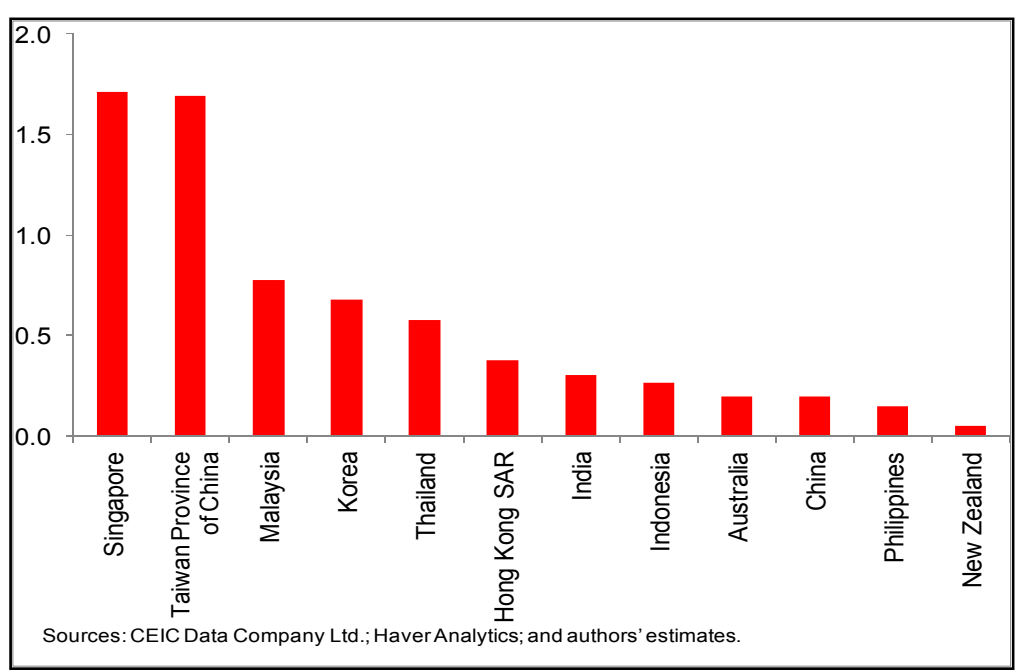

\section{CONCLuSIONS}

This paper has constructed a new index to assess overall financial conditions in Asia. The motivation for this is twofold. First, focusing on the level of the policy interest rate sheds light on only one dimension of overal financial conditions facing the economy, as an array of financial variables, in turn influenced by the policy stance, also play an important role. A financial condition, indeed, could therefore be constructed that summarizes these dynamics. Second, most of the macroeconomic variables that are an integral part of the policymaking are either unobservable (such as output gap and the "neutral" rate of interest) or become available with a substantial time lag (such as GDP growth and unemployment). Financial variables, on the other hand, are readily observable and hence can provide an important real time information to policymakers.

To construct the FCI for a group of Asia and Pacific economies we use two different methodologies - a VAR-based weighted sum approach, and a GDFM-based principle component approach. While the FCIs constructed based on these methologies proved to have comparable performance, their combination turned out to have better predictive power in forecasting GDP.

Looking at changes in FCIs over the last few years confirms their leading indicator property. Major turning points in economic activity were found to be preceded by turns in FCIs. Overall financial conditions in the Asia and Pacific region were relatively accommodative before the breakout of the crisis in 2008:Q3. Swings in equity markets were a major factor behind the tightening of financial conditions during the crisis and the recovery thereafter. Strong policy reactions to the crisis also contributed to rapid recovery of financial conditions. After reaching new local peaks, financial conditions began to tighten in 2010. Policy normalization has played a part, but much of the tightening stemmed from the moderation in equity market gains as well as the strengthening of exchange rates. Continued recovery in credit growth, on the other hand, has boosted overall financil conditions and contributed favourably to overall economic conditions in late 2010 . 


\section{DATA APPENDIX}

Here we present the specifics of data used for each economy under both VAR-based weighted sum approach and GDFM-based principle component approach.

\section{(i) VAR}

We use data on real GDP, equity prices, effective exchange rate, lending rate/spread, and bank credit to the private sector. ${ }^{11}$ The data is of quarterly frequency, covering the period between 1990 and 2010 (or shorter depending on data availability). All variables are in real terms, deflated by consumer price index (CPI) and one-year-ahead inflation forecast in the case of lending rate, and expressed in year-on-year percentage change (except real lending rate/spread). ${ }^{12}$ Data sources are International Financial Statistics (IFS) for GDP, effective exchange rate, bank credit and CPI. The data on equity prices and interest rates are taken from CEIC Data Company and Haver Analytics. The data source for one-year-ahead inflation forecasts is Consensus Economics Inc.

\section{(ii) GDFM}

In GDFM, we consider monthly (seasonally unadjusted) data from 2000 up to January 2011. As in the VAR methodology, we use a measure of interest rate spread, nominal exchnage rate, stock market indices, and nominal credit growth for each economy. We then calculate year-on-year growth rates (except for the interest rate spreads, which are in levels) and standardize the data before calculating the FCI. Inflation is the CPI inflation CEIC Data Company for each economy. All the other data are from Haver Analytics, unless otherwise stated. The data codes are given in paranthesis.

\section{$\underline{\text { Australia }}$}

Interest rates: Official cash rate (AUEROCR@ANZ), Treasury Bond 5-years (AUERG5V@ANZ), 3-Month London Interbank Offered Rate (AUVL3M@ANZ).

Exchange rate: Trade-Weighted Index (AUEXTWI@ANZ)

Credit: Credit including Securitized Housing Loans (AUSFCS@ANZ)

Stock Prices: MSCI Share Price Index (AUNFKML@ANZ), Share Price Indices (AUEFK200@ANZ)

\section{$\underline{\text { China }}$}

Interest Rates: 3-Month Certificates of Deposit (N924RD3M@EMERGEPR), 90-day Interbank Rate (N924RI3@EMERGEPR), 1-Year Deposit Rate (N924RD1Y@EMERGEPR). Exchange Rate: Broad Nominal Effective Exchange Rate (N924XJNB@EMERGEPR) Credit: Private Credit (CEIC Data Base)

\footnotetext{
${ }^{11}$ Claims on private sector of other depositor corporations are used to ensure consistency across economies.

${ }^{12}$ Exogenous variables included in the VARs to enhance the goodness of fit in some economies are the VIX and U.S. GDP growth which capture global factors.
} 
Stock Prices: Dow Jones Shanghai (N924FKS@EMERGEPR), MSCI Share Price Index (N924KMGL@EMERGEPR)

Hong Kong SAR

Interest Rates: 3-month Interbank Rate (N532RI3@EMERGEPR), Savings Deposit Rate (N532RDSV@EMERGEPR), Best Lending Rate (N532RL@EMERGEPR)

Exchange Rate: Broad Nominal Effective Exchange Rate (N532XJNB@EMERGEPR)

Credit: Loans and Advances to Customers: Total (N532FL@EMERGEPR)

Stock Market: MSCI Share Price Index (N532KMGL@EMERGEPR), Stock Price Index: Hang Seng Bank (N532FKH@EMERGEPR)

$\underline{\text { India }}$

Interest Rates: India: Bank Rate (N534RD@EMERGEPR), Repo Rate (N534RP@EMERGEPR), Reverse Repo Rate (N534RR@EMERGEPR)

Exchange Rate: Broad Nominal Effective Exchange Rate (N534XJNB@EMERGEPR)

Credit: Credit to the Commercial Sector (N534FBAY@EMERGEPR)

Stock Market: MSCI Share Price Index (N534KMGL@EMERGEPR)

Indonesia

Interest Rates: Bank Indonesia Rate (N536RTAR@EMERGEPR), SBI Discount Rate: 3-months (N536RD3M@EMERGEPR)

Exchange Rate: Broad Nominal Effective Exchange Rate (N536XJNB@EMERGEPR)

Credit: Banking System: Claims on Private Enterprises (N536FBCP@EMERGEPR)

Stock Market: Stock Price Index: Jakarta Composite (N536FKJ@EMERGEPR), MSCI Share

Price Index (N536KMGL@EMERGEPR)

$\underline{\text { Japan }}$

Interest Rates: Target Rate: Uncollateralized Overnight Call Rate (JRICUONT@JAPAN), Basic Loan Rate (RIOR@JAPAN), 5-Year Benchmark Government Bond Yield (N158G5@JAPAN)

Exchange Rate: Nominal Effective Foreign Exchange Rate (EERBN@JAPAN)

Credit: Credit to Private Sector (CEIC Data Base)

Stock Market: Nikkei Stock Market (SM225@JAPAN), Nasdaq Standard: Average (NASAY@JAPAN)

Korea

Interest Rates: Bank of Korea Base Rate (N542RCT@EMERGEPR), Commercial Paper Yields: 91-day (N542RP3M@EMERGEPR), Treasury Bond Yields: 1-Year (N542RG1@EMERGEPR)

Exchange Rate: Broad Nominal Effective Exchange Rate (N542XJNB@EMERGEPR)

Credit: Claims on the Private Sector (N542FMAP@EMERGEPR)

Stock Market: Korea Composite \{KOSPI\} (N542FK@EMERGEPR), MSCI Share Price Index (N542KMGL@EMERGEPR)

Malaysia

Interest Rates: Fixed Deposit Rate: 3 months (N548RD3M@EMERGEPR), Treasury Bill Rate: 3month (N548RG3M@EMERGEPR), Government Bond Yield: 1-year

(N548RG1@EMERGEPR)

Exchange Rate: Broad Nominal Effective Exchange Rate (N548XJNB@EMERGEPR)

Credit: Banking System: Loans (N548FCB@EMERGEPR) 
Stock Market: Stock Price Index: FTSE Bursa (N548FKK@EMERGEPR), MSCI Share Price (N548KMGL@EMERGEPR)

New Zealand

Interest Rates: Official Cash Rate (NZNROCV@ANZ), Government Bond Yield: 5-year (NZNRG5@ANZ), Bank Bill Yield:90 days (NZNRb3@ANZ)

Exchange Rate: Trade-weighted Index (NZNXTWI@ANZ)

Credit: Credit Aggregates: Private Sector Credit (NZEFCP@ANZ)

Stock Market: Capital Index: NZSX All Indexes (NZNFKc@ANZ), MSCI Share Price Index (NZNFKMGL@ANZ)

$\underline{\text { Philippines }}$

Interest Rates: Reverse Repo Rate: Overnight (N566RVv@EMERGEPR), Interbank Call Loan Rate (N566RC@EMERGEPR), Time Deposit Rate: Short-term (N566RDTS@EMERGEPR)

Exchange Rate: Broad Nominal Effective Exchange Rate (N566XJNB@EMERGEPR)

Credit: Private credit (CEIC Data Base)

Stock Market: Stock Price Index: Manila Composite (N566FKML@EMERGEPR), MSCI Share Price Index (N566KMGL@EMERGEPR)

\section{$\underline{\text { Singapore }}$}

Interest Rates: Overnight Repo Rate (N576RR@EMERGEPR), 3-Month Interbank Rate (N576RI3@EMERGEPR), Government Bond Yield: 5-year (N576RG5@EMERGEPR) Exchange Rate: Narrow Nominal Effective Exchange Rate Index (N576Xjnn@EMERGEPR) Credit: Commercial Bank Loans (F576FLB@EMERGEPR) Stock Market: Stock Price Index (N576FKS@EMERGEPR),MSCI Share Price Index (N576KMGL@EMERGEPR).

\section{Thailand}

Interest Rates: Policy Target Rate (N578RTAV@EMERGEPR), Commercial Banks Time Deposit Rate: 3-month (N578RD3M@EMERGEPR), Government Bond Yield: 5-years (N578RG5@EMERGEPR)

Exchange Rate: Broad Nominal Effective Exchange Rate (N578XJNB@EMERGEPR) Credit: Private Credit (CEIC Data Base)

Stock Market: Stock Price Index: Bangkok (N578FKB@EMERGEPR), MSCI Share Price Index (N578KMGL@EMERGEPR)

Taiwan Province of China

Interest Rates: Central Bank of China Rediscount Rate (N528RD@EMERGEPR), Commercial Papers: 31-90 days (N528RCP1@EMERGEPR), Government Bond Yield: 10-year (N528RG10@EMERGEPR).

Exchange Rate: Broad Nominal Effective Exchange Rate (N528XJNB@EMERGEPR) Credit: Private Credit (CEIC Data Base)

Stock Market: Stock Price Index (N528FKTW@EMERGEPR), MSCI Share Price Index (N528KMGL@EMERGEPR) 


\section{REFERENCES}

Chamberlain, G. and M. Rothschild, 1983, Arbitrage, Factor Structure and Mean Variance Analysis on Large Asset Markets, Econometrica, No. 51, 1305-24.

Dudley, W. C., 2010, “Comments on Financial Conditions Indexes: A New Look after the Financial Crisis," Remarks at the University of Chicago Booth School of Business Annual U.S. Monetary Policy Forum, New York City (February 26).

Forni, M., M. Hallin, M. Lippi, and L. Reichlin, 2005, The Generalized Dynamic Factor Model: One-Sided Estimation and Forecasting, Journal of the American Statistical Association, No. 100, pp. 830-40.

Forni, M. and M. Lippi, 2001, "The Generalized Dynamic Factor Model: Representation Theory," Econometric Theory, No. 17, 1113-41.

Geweke, J., 1977, The Dynamic Factor Analysis of Economic Time Series Models, in D. J. Aigner and A. S. Goldberger (eds.), Latent Variables in Socio-Economic Models, NorthHolland, Amsterdam.

Guichard, S. and D. Turner, 2008, Quantifying the Effect of Financial Conditions on U.S. Activity, OECD Economics Department Working Paper, No. 635 (September).

Hatzius, J., P. Hooper, F. S. Mishkin, K. L. Schoenholtz, and M. W. Watson, 2010, "Financial Conditions Indexes: A Fresh Look after the Financial Crisis," NBER Working Paper No. 16150 (Cambridge, Massachusetts: MIT Press).

International Monetary Fund, 2009, Financial Conditions in Key Asian Economies, Regional Economic Outlook: Asia and Pacific (Washington, May).

- 2010, A Financial Conditions Index for Asia, Regional Economic Outlook: Asia and Pacific (Washington, October).

Sargent, T. J. and C. A. Sims, 1977, Business Cycle Modeling Without Pretending to Have Too Much A Priori Economic Theory, in C.A. Sims (ed.), New Methods in Business Cycle Research: Proceedings from a Conference, Federal Reserve Bank of Minneapolis, Minneapolis.

Stock, J. H. and M. W. Watson, 1989, "New Indexes of Coincident and Leading Economic Indicators,” NBER Macroeconomic Annual 1989, pp. 351-94 (Cambridge, Massachusetts: MIT Press). , 1998a, Business Cycle Fluctuations in U.S. Macroeconomic Time Series, NBER Working Paper No. 6528 (Cambridge, Massachusetts: MIT Press). 
1998b, Diffusion Indexes, NBER Working Paper 6702, National Bureau of Economic Research (Cambridge, Massachusetts: MIT Press).

- 2002, Macroeconomic Forecasting Using Diffusion Indexes, Journal of Business and Economic Statistics, No. 20, 147-62.

Swiston, A., 2008, “A U.S. Financial Conditions Index: Putting Credit Where Credit is Due,” IMF Working Paper No. 08/161 (Washington: International Monetary Fund). 